\title{
Workplace Restructuring in Nigerian Manufacturing Industries: Some Unanticipated Consequences and Employee Adaptation Strategies
}

\author{
LongeOlukayode \\ Faculty of the Social Sciences Ekiti State University, Ado-Ekiti, Nigeria
}

\begin{abstract}
This study investigated the unintended consequences of workplace restructuring and employees' adaptive responses in manufacturing organisations. Thetarget firms were purposively chosen because they shared the same characteristics and had embarked on extensive process of restructuring within the past five years. The employees of the selected companies where the data were collected were 3200. Using an appropriate sampling determination formula, stratified random sampling method was used to select 800 employees. However, 725 respondents fully participated in the study. Questionnaire was the major instrument employed for data collection. Data analysis procedure involved the use of both descriptive and inferential statistical tools. Two hypotheses were tested and results showed a positivecorrelation between organisational attributes (management structure, management style and organisational climate) and adaptation strategies.It was also established that unanticipated consequences of workplace restructuring can be significantly described by loss of co-workers cohesion, diminished employee morale and heightened employee workload. Findings further confirmed that a combination of coping mechanisms; proactive method of task pursuit and reactionary approach of intention to quit was simultaneously adopted as predominant adaptation strategies by the employees. The study concluded that workplace restructuring was a stressful process and inherently unpleasant for the workforce but could be moderated by developing supportive organizational attributes to reinforce employees' adjustment in restructured manufacturing organizations.
\end{abstract}

Key words: Work place restructuring, employee adaptation, performance, work- organization and change management initiative.

\section{Introduction}

The increasingly turbulent and dynamic business environment coupled with the need for increased performance are forcing organisations whether in the manufacturing or service industriesaround the world to continuously search for new sources of competitiveness. Globalisation and information technology further add pressures to the need of constantly reinventing ways to compete (Zupan and Ograjensek, 2004). In response to these and other factors, manufacturing industries in Nigeria are undergoing profound and pervasive restructuring in the workplace, in which the balance of benefits and risks depend largely on how well employees can adapt to the unintended social discomfort and dislocation at work caused by this radical managerial strategy. As Lawal and Jayeoba (2011) put it, "unknown to the management of these Nigerian organisations, the on-going retrenchment of their employees in the name of restructuring may have wrecked more havoc on the organisations than what management claimed have brought them about'. This ineffect is suggestive that restructuring in the workplaceis a seemingly agonising process, and inherently unpleasant for the workforce in organisations.

Dzawanda (2007), described workplace restructuring as the fundamental changes made to the structural properties of an organisation. More specifically, it is a broad agenda for acquiring and leveraging new competency, deploying new functionality and reconfiguring the work interface and process in work organisations. In this context, workplace restructuring is concerned with the act of dismantling or replacing the existing management structure by relevant goal oriented and competitive structure that will satisfy the needs of both the workforce and the organisation (Chataut, 2008). As such, this novel organisational strategyentails the three- dimensional transformation of the workplace social structure, which are the rightsizing of the workforce, delayering of the organisational hierarchies and the redesigning of the work structures in the organisation. Thus, the radical change management initiative is aimed at the improvement ofwork-organisations for the purpose of enhancing effectiveness and responsiveness to environmental changes through greater labour flexibility and adaptability in the workplace.

However, Pandit (2005)argued that,the surgical solution of workplace restructuring; overloading workroles, reducing workforce and cutting cost is not a healthy and sustainable way for the rejuvenation of any company. Hernandez-Leon (2004),Frenkel(2003)and Ulrich (2000) have in factlinked the revolutionary managerial action with hard-nosed human resource management practice in the work environment. Also, Hirsch 
and Sourcey(2006),Laosebikan(2005), Neilson and Sharma (2004), Kim (2003), Webster and Omar (2003) and Gaughan(2002)revealed that what is gained in terms of performance imperative is lost in other areas.For these reasons, one can assert that workplace restructuring is an intentional managerial strategy undertaken with a particular aim in view and actually has consequences that prevent the achievement of that aim.Most establishments that restructured in order to increase performancefound that what they have gained is virtually a restless and depressed workforce (Longe, 2012). Yet, responsive organisations must restructure to develop cultures that promote optimum employee adaptation.

According to Reio and Sutton (2006) employee adaptation is a proximal outcome of a socialization process of seeking coherence and stability in behaviours in organisations. As a result of adaption, employees are able to adopt new behavioural response that allows them to cope with change in the work environment. This involves the ability to adjust to new experience and reposition either negatively or positively in order to overcome prevailing obstacles of the changing condition of work in organisations.In other words, employees must reduce anxiety and at the same time increase commitment by exploring rational adaptation strategies to moderate the concomitant side-effect of workplace restructuring. The ability to adapt to this rapiddevelopment and to learn is an inseparable aspect of organisational working life (Loogma, 2009). The appropriate adage is "what cannot be avoided must be endured or accommodated". Brescian, Griffins and Rust (2009) opined that employee adaptation to change can particularly be an onerous task in an organisation. This notwithstanding, employees need to adapt by adopting effective coping methods when situational circumstances are at variance and run counter against theexisting expectations in the work-environment..

In contrast, what obtains as realities in organisations, particularly in the manufacturing industries in Nigeria is the reverse. On the surface, employees appears to be highly adaptable by adopting various subtle adaptation strategies, but these moves are usually counter-productive creating widespread confusion and disenchantment in work organisations.Employees have committed suicide, families and marriages disrupted and other various unanticipated social problems emerging because they cannot adjust to the sudden change that accompanies workplace restructuring (Longe, 2012).Consequently, what therefore arousedinterest in this study are the unintended social dysfunctions created as aftermath of restructuring in manufacturing organisations. Since, the radical managerial programme may be inevitable in revitalising industries and business firms, employee adaptation strategies have become more and more important for improving the performance domain in work-organisation. It is against this backdrop that this present study investigates the unanticipated consequences of workplace restructuring and the emerging range of adaptive responses of employees in terms of coping behaviours in manufacturing organisations.

\section{Conceptual Clarification}

The concept of workplace restructuring is relatively new, but the broad issues of re-fashioning of organisational work-practices with which it is concerned, have a relatively long history, dating back to the inception of capitalist industrialisation. As such, the term workplace-restructuring still connotes part of the continuous and innovative high performance work management practices in organisations. According to Mckinley and Scherer (2000), workplace restructuring refers to any major reconfiguration of internal administrative structure that is associated with an intentional management change programme. This view is consistent with Nickels (2002) and Bowman, Useem, Bhardury and Sigh's (1999) description of workplace restructuring which draws distinction between three types of restructuring in work organisations, namely; portfolio, financial and organisational restructuring. The notion of workplace restructuring as constructed in this study is synonymous with organisational restructuring and excludes the business portfolio changes that are part of portfolio restructuring as well as the financial changes, increasing debt levels or reducing free cash flow that are commonly associated with financial restructuring.

Commission of the European Communities (CEC)2002 and 2008), defines workplace restructuring as a modification of company workforce, that affects both the latter qualitative (skills and qualifications) required and its qualitative features (number of jobs) following adaptation to the management structure, organisation or production. The rationale for such an organisational rearrangement is to inject new work life, interest and enthusiasm into the workplace social structure (Confield, Campbell and McCannon, 2001).Ideally, workplace restructuring is the mantra for change and current global convention of managerial thought for concept of work transformation and performance in organisation. The radical change management programme has now gained currency as a strategic managerial approach for repositioning contemporaneous work-organisations. This is to enable the workforce to better fulfil their work roles and tasks relationship more efficiently and friendlyin the work-environment.

However, despite the acclaimed benefits of workplace restructuring, Reut (2003) asserted that, although the radical managerial programme does not possess the intensity of forest fire, butit does contain strong potentials ofontological job insecurity and heightened anxiety for employees in work-organisations. For example in Nigeria, the recent restructuring in the banking sector, which was motivated by the need to 
proactively put the industry on the path of global competitiveness created lot of social disruption and disorder in that industry. Apart from job erasures, laid off employees leave the banks with mixed feelings. Those employees that remained within the system continue to operate with some aura of sceptic loyalty (Nation Micro Economic Report, 2009). As observed by Szites and Coffin (2006), the pursuit of restructuring in organisations often leads to an unavoidable consequence of downsizing, thereby creating an anorexic workplace.Thus, as conceptualised in this study, workplace restructuring is a change initiative strategyinstituted by management in which employees are right-sized, downsized and laterized by compassionless efficiency to ensure the continuous achievement of organizational objectives.

From this perspective, a growing number of international evidence tends to support the fact that workplace restructuring has some negative side-effects as invisible black spots in work organisations (Quillan, 2007 and Hirsch and Sourcey, 2006, Frenkels, 2004). Several research studies have also highlighted some symbolic dysfunctions of workplace restructuring, as role overload and higher odds of damaged morale of managerial and non-managerial employees(Asok, 2005); disappearance of valued work friendship and broken social cohesion (Parry,2003); dropping employee retention rate (Nickels,2002); and work intensification and job insecurity (Butchell, Ladipo and Wilkinson, 2002). Given the magnitude of the unintendedconsequences of workplace restructuring, employees have now become self compelled to search for remedy seeking behaviours that will allow them to cope with the prevailing situational realities in the work environment. These quests have led to the reactionary two-factor adaptation model offered by Hullins (1999)and the proactive behavioural adjustment approach proposed by (Rose and Miller, 2000). These modes of adaptation imposed a sense of obligation on management to evolve appropriate organisational attributes in moderating the unintendeddysfunctions of restructuring in work-organisations

\section{Hypotheses}

This study is hinged on the following hypotheses:

Hypothesis One

$\mathbf{H}_{\mathbf{0}}$ : $\quad$ Unanticipated consequences of workplace restructuring cannot be significantly described as shortened job retention period, loss of co-workers cohesion, and heightened employee workload, and diminished employee morale.

$\mathbf{H}_{1}$ : $\quad$ Unanticipated consequences of workplace restructuring can be significantly described as shortened job retention period, loss of co-workers cohesion, and heightened employee workload and diminished employee morale.

\section{Hypothesis Two}

$\mathbf{H}_{\mathbf{0}}$ : There is no significant relationship between organisational attributes and employee adaptation strategies in post restructuring context.

$\mathbf{H}_{1}$ : There is significant relationship between organisational attributes andemployee adaptation strategies in post restructuring context.

\section{Method}

The study was carried out in four purposively selected manufacturing firms, which had embarked on a process of restructuring within the past five years. This choice was influenced by the position which the organisations occupied as industrial giants and market leaders in their respective trade groups. The population of the target companies where the data were collected was 3,200 . The sample size was 800 by using the statistical formula $\left(\mathrm{N}=(\mathrm{Z} \alpha)^{2} \mathrm{pq} / \mathrm{d}^{2}\right)$, where $\mathrm{Z} \alpha$ is the confidence interval of $1.096^{2}, \mathrm{p}$ is the perception of the workforce adaptation $(0.25), \mathrm{q}$ is $1-0.25$ (perception of workforce adaptation and $\mathrm{d}$ is the tolerance level of 0.03 . Stratified random sampling technique was employed for the selection of the respondents. The basic criteria of inclusion in the sample were employee organisational tenure of not below 5 years and job rank.

Questionnaire was the main instrument used for data collection. The researcher administered 800 copies of questionnaire and 725 were retrieved and found useable for analysis with a response rate of $91.6 \%$. The main part of the questionnaire comprises 40 questions answered in Likert Scale format, which was used to measure pertinent constructs of the study. Each item of a construct was presented with five alternative responses ranging from extremely low, low, indifferent, high and extremely high.This was done to determine the unintended impact and retrospective issues related to workplace restructuring. Insights into employees' adaptation strategies and organisational attributes influencing the employees' coping mechanism in post restructuring context were also sought. The questionnaire also asked for details of respondents age, gender, marital status, educational status, organisational tenure and job rank.

The survey followed all the required ethical procedureswith an information cover-page describing the motivation for the study as well as assuring respondents of the confidentiality of their responses. The research instrument was pilot tested using a sample of 75 employees in another organisation that had undergone 
restructuring in the past. Each scale of the construct was evaluated for reliability. The results reflected appropriate adequacy. The Cronbach alpha of variables ranged between 0.71 and 0.84 respectively.Demographic data of respondents were coded and subjected to analysis using the descriptive statistical tool of frequency counts, percentages, mean and standard deviation. Inferential statistics of multiregression was used to test hypotheses. The decision criteria for acceptance or rejection of the hypotheses were set at 0.05 alpha level.

\section{Results}

Findings on the personal characteristics of the respondents show that their mean age is 33.3 years with standard deviation of 6.85 years. The gender of respondents revealed a disproportionate representation, where male accounted for $67.4 \%$ and female constituted $32.6 \%$ of the sampled population. This gives a ratio of $2: 1$ across the gender group skewed in favour of male. The plausible reason for this, is that women employees are still not numerically represented as their men counterparts in manufacturing companies in Nigeria.(FITC, 2011). On marital status, less than three-quarters (71.6\%) of the respondents were married and more than onequarter $(28.4 \%)$ were either single, separated, divorced or widowed. A significant proportion $(76.7 \%)$ of the respondents possessed low educational status, belowOrdinary National Diploma while the remaining (23.3\%) of the samplehad university and professional backgrounds. Employees' organisational tenure in their current establishment presented a mean of 9.9 years with a standard deviation of 3.6 years. They had also been in their current position for an average of 3.5 years, with a standard deviation of 1.8 years.

Exploring the unanticipated consequences of workplace restructuring, the recorded mean-score derived from the Likert scale with numeric value 1-5 (extremely low-extremely high) for the total sample ranged from 3.65 (lowest) to 4.56 (highest), signifying a relatively strong and negative unintended impact as exemplified by the selected indicators in Table I. Loss of co-workers cohesion has the highest mean value (4.56) followed by shortened employee job retention period (4.07), heightened employee workload (3.76) and diminished employee morale (3.65),thereby presenting these indicators as having high discomfort level on employees. Significantly on the whole, more than eight (8) out of ten (10) that is, over $(80 \%)$ of the respondents agreed to the strong negative effects of the unanticipated consequences of workplace restructuring on employees work roles.

Table 1: Mean Rating of Responses on Some Unanticipated Consequences of Workplace Restructuring.

\begin{tabular}{|c|l|l|}
\hline Indicators & Mean value & $\mathbf{N}=\mathbf{7 2 5}$ \\
\hline Loss of co-workers cohesion & More than 4 & $90.20 \%(654)$ \\
& Less than 4 & $9.80 \%(71)$ \\
\hline Shortened employee retention period & More than 4 & $89.50 \%(649)$ \\
& Less than 4 & $10.50 \%(76)$ \\
\hline Heightened employee workload & More than 3 & $85.10 \%(646)$ \\
& Less than 3 & $14.90 \%(79)$ \\
\hline Diminished employee morale & More than 3 & $84.70 \%(614)$ \\
& Less than 3 & $15.30 \%(111)$ \\
\hline
\end{tabular}

Source: Field Survey, 2012.

In a ranking order, data presented in Table 2 show that the popular coping strategies adopted by the workforce are proactive method of task pursuit (64.8\%) conformity (60.8\%) and / or "Problem solving" (58.8\%) or at the extreme, are reactionary approaches, job withdrawal method of planned intention to quit (50.5\%) workwithdrawal method of planned avoidance $(50 \%)$ and reducing of work effort $(39.3 \%)$. It is of significance to note that the respondents hardly used the work withdrawal method of rebellion (8.1\%) absenting from work $(4.4 \%)$ and arriving late $(3.9 \%)$ as adaptation strategies. These results depicted that a combination of coping mechanisms;proactive method of work approach and reactionary approach of job withdrawal were simultaneously adopted as adaptation strategies by the employees.

Table 2: Descriptive Analysis of Employee Adaptation Strategies

\begin{tabular}{|c|c|}
\hline Adaptation Strategies & $\begin{array}{l}\text { Respondents } \\
\mathrm{N}=725\end{array}$ \\
\hline \multicolumn{2}{|l|}{ Proactive Approach } \\
\hline Task pursuit & $\begin{array}{l}64.8 \% \\
(470)\end{array}$ \\
\hline Conformity & $\begin{array}{c}60.8 \% \\
(441)\end{array}$ \\
\hline Problem - Solving & $\begin{array}{l}58.8 \% \\
(426) \\
\end{array}$ \\
\hline \multicolumn{2}{|c|}{ Reactionary Approach } \\
\hline Intention to quit & $\begin{array}{l}50.5 \% \\
(366)\end{array}$ \\
\hline Planned avoidance & $49.9 \%$ \\
\hline
\end{tabular}


Workplace Restructuring in Nigerian Manufacturing Industries: Some Unanticipated....

\begin{tabular}{|c|c|}
\hline & $(362)$ \\
\hline Reducing of work effort & $39.3 \%$ \\
& $(285)$ \\
\hline Retaliation & $21.9 \%$ \\
& $(159)$ \\
\hline Rebellion & $8.1 \%$ \\
& $(59)$ \\
\hline Absenting from work & $4.4 \%$ \\
& $(32)$ \\
\hline Arriving late & $3.9 \%$ \\
& $(28)$ \\
\hline
\end{tabular}

Source: Field Survey, 2012.

\section{Test of Hypotheses}

Hypotheses 1:Unanticipated consequences of workplace restructuring cannot be significantly described by shortened job retention period, loss of co-workers, cohesion, heightened employee work load and confusion of work roles.

The first hypothesis was tested using multiple regression statistical analysis. Data presented in Table 3 show the estimated co-efficient of the unanticipated outcomes of workplace restructuring. The bottom-line of the table indicates the predictor variable, while four estimated coefficients are shown on the second column. These are $0.231,2.45,0.175$ and 0.216 . Next to the estimated co-efficient are the standard errors for each of the response factors which are 0.012 for shortened job retention period (SJRP), 0.016 for loss of co-workers cohesion (LCC), 0.018 for heightened employee workload (HEWL) and 0.019 for diminished employee morale (DEM). The corresponding $t$ statistics for each of these factors are 16.042 for (SJRP), 11.206 for (LCC), 12.742 for (HEWL) and 13.334 for (CWR). All the response factors had a significance of 0.000 in a one-tailed test. Thus, the null hypothesis was therefore rejected and the alternative hypothesis accepted because $r=0.892$, $\mathrm{df}=319<0.05$ which implies that unanticipated consequences of workplace restructuring can be significantly described by shortened job retention period, loss of co-workers cohesion, heightened employee workload and diminished employee morale.

Table 3: Estimated Co-efficient of the Unanticipated Consequences of Workplace Restructuring.

\begin{tabular}{|c|c|c|c|c|c|c|c|}
\hline $\begin{array}{l}\text { Response } \\
\text { Variable }\end{array}$ & B & $\begin{array}{l}\text { Unstandardised Co- } \\
\text { efficients }\end{array}$ & $\begin{array}{c}\text { Standardised Co- } \\
\text { efficients }\end{array}$ & T & Sig. & & $\begin{array}{c}\text { Co-linearity } \\
\text { Statistics }\end{array}$ \\
\hline Standard Error & Beta & Tolerance & VIF & B & Std. Error \\
\hline CONSTANT & 1.098 & 0.55 & & 13.301 & .000 & & \\
\hline SJRP & .231 & .012 & .442 & 16.042 & .000 & .553 & 1.394 \\
\hline LCC & .245 & .016 & .251 & 11.206 & .000 & .883 & 1.296 \\
\hline HEWL & .175 & .018 & .316 & 12.772 & .000 & .675 & 1.003 \\
\hline DEM & .216 & .019 & .416 & 13.334 & .000 & .762 & 1.239 \\
\hline
\end{tabular}

Alpha level: 0.05

Source: Field Survey, 2012

Hypothesis 2: Organisational attributes will not significantly mediate the effect between unanticipated consequences of workplace restructuring and employee adaptation strategies in post restructuring context.

Recognising the multi-dimensionality of the variables of organisational attributes, a multivariate statistical technique (Pearson's correlation) was utilized to test the second hypothesis. Thus, a Likert scale format was used to assess the mediating effect of each indicator management structure, management style and organisational climate. Ranking attached to the indicators vary with response from strongly agree: 5 points and strongly disagree 1 point. The total score value of these indices were pulled together to allow the determination of the strength of relationshipbetween the unanticipated consequences of workplace restructuring and adaptation strategies which involved the use of seventeen items on multiple bases in the questionnaire. The cut-off strength of relationship (r) in the correlation is $16 \%$ while less than 16 percent is regarded as weak strength of relationship and thus not significant.

Data in Table 4 indicate the results of the Pearson's correlation on the perceived unanticipated consequences of workplace restructuring, employee adaptation strategies and organisational attribute of management structure. The strength of relationship $\mathrm{r}=0.349(35 \%)$. The relationship produced an observed $\mathrm{p}$ value of 0.001 . Statistical evidence on management style also indicates that $(r=0.321(32 \%))$. Theseresultsshowed that there were positive mediating effects between the variable of management structure, management style and employee adaptation strategies. Similarly, organisational climate showed a positive and significant mediating effect with strength of relationship, $r=0.330(33 \%)$. Consequently, there appears to be a commonality of support in the interaction of the organisational attributes, moderating the normative side-effects of workplace restructuring and the choice of the employees coping strategies adopted by the employees in the post-restructuring context. Thus, the null hypothesis was rejected while the alternative one was upheld. 
Workplace Restructuring in Nigerian Manufacturing Industries: Some Unanticipated....

Table 4: Pearson's Correlation Analysis of the Relationship between Organisational Attributes and Adaptation Strategies

\begin{tabular}{|c|c|c|c|}
\hline & \multicolumn{3}{|c|}{ Organisational Attributes } \\
\hline $\begin{array}{c}\text { Unanticipated Consequences } \\
\text { and Mode of Adaptation }\end{array}$ & Management Structure & Management Style & Organisational Climate \\
\hline $\mathrm{N}$ & 725 & 725 & 725 \\
\hline Pearson & 0.349 & 0.321 & 0.330 \\
\hline $\mathrm{R}$ & $35 \%$ & $32 \%$ & $33 \%$ \\
\hline P-value & 0.000 & 0.000 & 0.000 \\
\hline Decision & Sig & Sig & Sig \\
\hline Reason & $\mathrm{P}<0.005$ & $\mathrm{P}<0.005$ & $\mathrm{P}<0.005$ \\
\hline
\end{tabular}

Source: Field Survey, 2012

\section{Discussion of Findings}

This paper contributes to the understanding of the concomitant side-effects of workplace restructuring, employees' coping strategies and the organisational attributes influencing the adaptive response of the workforce in post-restructuring context in the manufacturing industries. The findings of the study, thus contributed to the growing empirical evidence that workplace restructuring does contain some unintended consequences which served as inhibitory dynamics preventing restructured organisations and employees therein from developing from disengaged zone to engaged zone of performance in the work environment. This position has been buttressed by the results of earlier studies carried out by Hirsch and Sourcey, (2006); Asok, (2005); Nickels (2002); McKinley and Scherer, (2000). Literature suggests the unanticipated invisible black spots of restructuring in the workplace as loss of co-workers cohesion, heightened employee workload, confusion of work-roles. These were confirmed by the results ofour analysis. The culminating effects of these intended consequences of workplace restructuring compelled employees to adopt appropriate coping or adaptation strategies as remedy seeking behaviours in order to put themselves in harmony and adjust positively to the changing condition of work in the post-restructuring era.

Within the context of this study, adaptation strategies refer to the way and manner in which employees have made themselves whole and come into terms or contend with the unintended dysfunctions of restructuring in the manufacturing industries. To this end, Rose and Miller (2000), posited two main ways in which employees can adapt or cope with the impulsive and aversive work conditions in the organisational environment. These are the reactionary and proactive coping mechanisms. Empirical evidence from this study, did confirm the use of these multiple coping methods by employees in post restructuring period in the manufacturing industries. Our finding corroboratesHullins (1999)and Rose and Miller (2000), who submit that the dissatisfaction at work is inherently unpleasant and therefore compels dissatisfied employees to search for ways of reducing their disaffection. By and large, the adoption of proactive coping mechanism as mirrored in this study could still be construed to imply that employees were still displaying some calculative commitment to work as an adaptive response inthe post-restructuring period.

As for the first hypothesis, the impact of the reversed consequences of workplace restructuring can be explained by factors like shortened retention period, disruption of work - friendship and diminished employee morale. This revelation upholds the acceptance of the alternative hypothesis, while the null hypothesis was rejected. Our result therefore suggests that workplace restructuring is ridden with various unexpected complex ambiguities and tendencies which create crisis of workforce adjustment in the manufacturing industries in the post restructuring era. This empirical observation accords with the views of many researchers that what most organisations that restructured in order to increase performance foundas gains are angry and disenchanted, employees at a time when they need good spirit and innovation to survive (Longe, 2012; Lawal and Jayeoba 2011; Quillan, 2007; Asok, 2005; Kirimaki, Vatitera, Elvaino, Peatit and Vitanen 2003; Lewin and Johnston, 2000).In contrast therefore, the general managerial argument that the relief of not losing one's job will overshadow any negative feelings employees might have in post restructuring period is not only an illusory thought, but also an erroneous assumption.

In the second hypothesis, the mediating effect analysis revealed that organisational attributes (management structure, management style and organisational climate) significantly influenced the relationship between the unanticipated consequences of workplace restructuring and employee adaptation strategies in the post restructuring context. This affirmed a statistically determinate dependency on the moderating effect of organisational attributes and the coping mechanisms adopted by employees in thepost-restructuring context, thus,confirming the second hypothesis for the study. Though each selected organisation had distinct features, they shared commonalities in terms of organisational functioning and practice and in their mediating effect on the adaptation strategies adopted by their employees. Thus, the results offered significant empirical support for the general consensus on organisational attributes that the features employees perceive as benigh and in which they are able to achieve their desires at work are seen as the best coping option to influence their adaptive response in post restructuring era (Garry, 2002). 


\section{Conclusion and Recommendations}

This study examined the unintended negative dynamics of workplace restructuring and the remedy seeking behavioursof employeesin the manufacturing industries in Nigeria. Our results support the mounting body of empirical evidence that the change management model carries with it hard multiple realities described as chaos in organisations destroying and disrupting the very thing that it is seeking to enhance and improve(Asok, 2005; and Nickels, 2002). These invisible dark sides of workplace restructuring are not only agonisingly toughbut inherently creatingemployees' feelings of work alienation in the manufacturing environment. The study also highlights the adaptation strategies employed by employees as coping mechanismsin post restructuring context.The review of literature provides strong evidence of moderating effect of organisational attributes influencing the adaptation strategies adopted by employees in post-restructuring context. Our study empirically substantiated the result of earlier studies in this regard. Given the results of our study, the non-linearity of workplace restructuring has made the revolutionary managerial approach a heartbreaking challenge resulting into crisis of workforce adaptation in the organisational environment.

Thus, from the foregoing, the findings of the study have led to the following recommendations:Workplace restructuring in the workplace must serve as an organisational saviour to help manufacturing industries to realize their full potentials and goals rather than creating inhibiting dynamics for employee performance. Empirical evidence from the study indicates confusion of roles as part of the unintended side-effects of the change management initiative. As such,management must ensure that organisation's action and communication are detail enough to give every employeea clearer understanding of the part they need to play in ensuring a successful implementation of workplace restructuring interventions.As workplace restructuring efforts proceed, it is increasingly important for management to introduce manpower development programmes that will help to createwell-rounded and multifaceted workforce that will respond positively to the emerging dysfunctions of workplace restructuring.

Survivor employees must also be counselled to take intelligent sacrifice and accept more roles and responsibilities in their newly restructured organisations. Employee centred workplace climate, functional and goal oriented management structure and participative management style which emphasis support, with occasional use of unilateral power to obtain compliance must be put in place. These organisational attributes should be cultivated through guiding norms, values and expectations to ensure optimum employee flexibility in post-restructuring context. Given our current results, management in manufacturing organisation should strive to truly relinquish much of the work-control in post-manufacturing context, give authority to greater involvement and provide surviving employees with opportunity for self-empowerment and accomplishment in their workorganisation.

However, the present study is not without some limitations. First, the scope of the research study centred mainly on manufacturing organisations alone, it is not certain that similar results would be established if the same type of study is conducted in other industries. Second, the study sample was derived from smaller sample which may also pose some threats to the generalizability of the study. It would be advisable to use larger sample in future researches in order to be able to make appropriate generalization with a view to attaining universal validity. Despite these limitations, the study makes significant contribution to knowledge and most of the generalisations that emerged from this study were suggestive and conclusive of workplace restructuring interventions and adaptive response of employees in manufacturing industries in a reforming and developing nation like Nigeria.

\section{References}

[1]. Ashok, S. (2005).,Mahut Group: A Failed Restructuring. Asian Case Research Journal vol.9 Issue (1) pp 1-23.

[2]. Burchell B, Ladipo, D. and Wilkinson, F. (2002)., Job Insecurity and Work Intensification. London, Routledge Press.

[3]. Brescian, W, Griffins, A. and Rust, H. (2009)., Assessment of Adaptation to Change at North State University Paper Presented at the University Conference Centre

[4]. Commission of European Community, (2002)., Anticipating and Managing Change: A Dynamic Approach to the Social Aspects of Workplace Restructuring. Commission of European Commission (CEC), Paper Brussels, Germany.

[5]. _ _ _ (2008)., Restructuring and Employment: The Contribution of the European Union. Commission of European

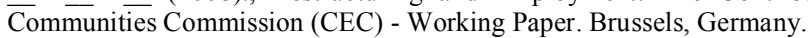

[6]. Chataut, B. (2008)., Workplace Restructuring in Nepal Telecomms and Foundation of Organisation Structure. Paper Delivered at the $4^{\text {th }}$ Annual Anniversary Souvenior of Nepal Telecomms.

[7]. Confield, D. Campbell, K. and McCannon, H. (2001)., Working in a Restructured Workplaces; Challenges and New Directions for the Sociology of Work C.A; London, Sage Thousand Oaks.

[8]. Donaldson, G. (1994)., Corporate Restructuring: Managing the Change Process from Within, Harvard Business School Press, First edition, $658,1612 \mathrm{O} / \mathrm{S}$.

[9]. Dzwanda, B. (2007)., The Restructuring and Privatization Process. Paper Presented to the Union of African Railways, $7^{\text {th }}$ Meeting on Restructuring and Privatization-Kinshasa, Congo.

[10]. Financial Institutions Training Centre(2011)., Gender Relations Management in the Workplace; The Nigerian Experience, Lagos Nigeria, Financial Institutions Training Centre (FITC) Publication.

[11]. Frenkel, S. (2003)., The Embedded Character of Organisational Restructuring, Journal of Works and Occupation. Vol. 30 pp135153 . 
[12]. Gaughan, P. (2002)., Merger, Acquisition and Corporate Restructuring, Wiley Publications New York, USA.

[13]. Garry, A. (2002)., Impact of Work Climate on Organisational Performance. Personnel Psychology, Vol. 56, pp 383 - 404.

[14]. Hernandez-Leon, R. (2004)., Restructuring at the Source: Works and Occupation Vol. 31 Pp 424-452

[15]. Hirsch, P. and Sourcey, M. (2006)., Organisational Restructuring and its Consequences - Rhetorical and Structural, Annual Review of Sociology vol. 32,August, pp 171-189.

[16]. Isamah, A.(2004)., Corporate Restructuring: The Challenge of Change as Motivator. Paper

[17]. Delivered at the Management Training Retreat, Nigeria Air Space Management Agency, (NAMA), Lagos, Nigeria. May, $26^{\text {th }}$.

[18]. Kim, W. (2003)., Economic Crisis, Downsizing and Lay Off Survivors Syndrome, Journal of Contemporary Asia vol. 33 April, pp449-464.

[19]. Lawal A. and Jayeoba, F. (2011)., Downsizing and Psychological Health of Survivors of Downsizing in Nigerian Organisations. Moderatoring Role of Paternalistic Leadership; Ife Social Science Review, No 1 Vol. 24, pp201-210.

[20]. Laosebikan, J. (2005).,Re-engineering and Employees' Productivity in the Bank-Sector inNigeria.Unpublished PhD ThesisDepartment of Adult Education, University of Ibadan, Ibadan.

[21]. Lewin, J. and Johnston, W. (2000).,The Impact of Downsizing and Restructuring on Organisational CompetitivenessCompetitiveness Review, January, pp 65-84.

[22]. Longe, O.J. (2012).,Workplace Restructuring and Employee Adaptation in Selected Manufacturing Industries in SouthwesternNigeria. Unpublished Ph.D Dissertation, ObafemiAwolowo University Ile-Ife, Nigeria.

[23]. Loogma, K. (2009)., How Workers Cope with Changes in Working Life: Adaptation strategiesin Towards Integration of Work and Learning (Eds) Stressform, M and Tynjala P, Tallin University, Estonia Spring Science Business Media Publication, Institute of Educational Research.

[24]. McKinley, W. and Scherer, A. (2000)., Some Unanticipated Consequences of Organisational Restructuring. Academy of Management Review, October, vol. 25, no. 4 pp 735-752.

[25]. Neilson, G. and Sharma, D. (2004)., New Wave of Organisational Restructuring. Academy of Management Review.Vol. 2 June pp. $34-46$

[26]. Nickels, J. (2002)., The Invisible Cost of Organisational Restructuring. A Theory of Disengagement, University of Wales, College of Medicine and Centre for Health Leadership (Wales).

[27]. Pandit, S. (2005).,Insights on Organisational Transformation, New Delhi, India: Tata McGraw Hill Publishing Company Ltd.

[28]. Parry, J. (2003)., Restructuring in the Former Coal Industry of the South Wales Valley, Work, Employment and Society. British Sociological Association.Vol. 17 February pp227-246.

[29]. Quillan, M. (2007)., Organisational Restructuring (Downsizing OHS Regulation and Worker's Health and Well-being. Working paper No. 2- National Research Centre for OHS regulation, Australian National University. South Wales, Sydney,Australia.

[30]. Reio, T. and Sutton, F. (2006)., Employees Assessment of Work Related Competencies and Workplace Adaptation, Human Resource Development Quarterly, vol 17, No2, Wiley Interscience Periodicals, pp. 315-324

[31]. Ruet, J. (2003)., Against the Current-Organisational Restructuring of State Electricity Board, New Delhi, Manohar, India.

[32]. Szites, H. and Coffin, C. (2006), Delayering Global Business UK; Bloomsbury Publishing Plc Urich, D. (2000)., Human Resources Champion Boston Massachusettes, USA; Harvard Business School Press.

[33]. Webster E, and Omar R, (2003)., Organisational Restructuring in Post Apartheid South Africa, Journal of Work and Occupation, Vol. 30 pp 194-213

[34]. Zupan, N. and Ograjensek, I. (2004)., The Link Between Human Resource Management and Company Performance, Journal of East-West Business 10 (11),pp 105-119. 